\title{
Metabolic Profiling of Praziquantel-mediated Prevention of Opisthorchis viverrini-induced Cholangiocyte Transformation in the Hamster Model of Cholangiocarcinoma
}

\author{
PATTAMA PROMMAJUN ${ }^{1,2}$, JUTAROP PHETCHARABURANIN $^{1,2,3}$, NISANA NAMWAT $^{1,2}$, \\ PORAMATE KLANRIT ${ }^{1,2}$, PRAKASIT SA-NGIAMWIBOOL ${ }^{2,4}$, MALINEE THANEE $^{5}$, \\ HASAYA DOKDUANG ${ }^{2}$, YINGPINYAPAT KITTIRAT ${ }^{1,2}$, JIA V. LI $^{6}$ and WATCHARIN LOILOME ${ }^{1,2,3}$ \\ ${ }^{1}$ Department of Biochemistry, Faculty of Medicine, Khon Kaen University, Khon Kaen, Thailand; \\ ${ }^{2}$ Cholangiocarcinoma Research Institute, Khon Kaen University, Khon Kaen, Thailand; \\ ${ }^{3}$ Khon Kaen University International Phenome Laboratory, \\ Northeastern Science Park, Khon Kaen University, Khon Kaen, Thailand; \\ ${ }^{4}$ Department of Pathology, Faculty of Medicine, Khon Kaen University, Khon Kaen, Thailand; \\ ${ }^{5}$ Faculty of Medical Science, Nakhonratchasima College, Nakhon Ratchasima, Thailand; \\ ${ }^{6}$ Department of Metabolism, Digestion and Reproduction, Faculty of Medicine, \\ Imperial College London, South Kensington Campus, London, U.K.
}

\begin{abstract}
Background: Opisthorchis viverrini (Ov) infectioninduced cholangiocarcinoma (CCA) is a major public health problem in northeastern Thailand. Praziquantel was shown to prevent CCA development in an Ov-infected hamster model; however, the molecular mechanism remains unknown. Materials and Methods: In this study, we used a hamster model with $\mathrm{Ov}$ and $\mathrm{N}$-nitrosodimethylamine-induced CCA to study the mechanisms of praziquantel action. The liver tissues from the hamsters with and without praziquantel treatment were analyzed using ${ }^{1} H$ nuclear magnetic resonance spectroscopy. Results: A total of 14 metabolites were found to be significantly different between the two groups. Furthermore, the combination of acetate, inosine and sarcosine was shown to exert an anti-inflammatory effect through interleukin-6 inhibition in a macrophage cell line, suggesting a mechanism by which praziquantel may prevent inflammation caused by $O v$, cholangiocyte transformation and further CCA develpoment. Conclusion: These findings might avail the development of a preventive strategy for CCA in high-risk populations.
\end{abstract}

This article is freely accessible online.

Correspondence to: Watcharin Loilome, Department of Biochemistry, Faculty of Medicine, Khon Kaen University, Khon Kaen, 40002, Thailand. Tel: +66 43363265, e-mail: watclo@kku.ac.th

Key Words: Praziquantel, cholangiocarcinoma, anti-inflammation, metabolic profiling, nuclear magnetic resonance spectroscopy.
Cholangiocarcinoma (CCA), a malignancy of bile duct epithelial cells, is a major public health problem in Northeast Thailand, which has the highest incidence in the world of this disease (1). A parasitic infection caused by Opisthorchis viverrini $(\mathrm{Ov})$, a liver fluke, was identified as a cause of CCA in 1994 and is associated with CCA development (1). Upon liver fluke infection, CCA genesis is hypothesized to be initially induced via multiple mechanistic pathways, including mechanical damage caused by the fluke suckers, fluke toxic secretory products, and the host immunopathological response, leading to chronic inflammation (2). Moreover, the overproduction of reactive oxygen species and reactive nitrogen species from chronic inflammation results in tissue injury associated with CCA initiation and progression (3). In accordance with the hepatic changes first reported in 1978 in an Ov-infected hamster model, hyperplasia, adenomatous formations and periductal and portal scarring of the bile duct epithelium were also observed at 22 weeks post infection, although bile duct carcinoma was not seen at that time (4). In addition, a previous study showed that alone, $N$ nitrosodimethylamine (NDMA), a potential carcinogen, did not induce tumor formation in hamsters, but together with Ov infection, CCA was observed in a number of animals (5). Furthermore, histological changes, such as inflammatory reactions, bile duct proliferation, periductal fibrosis and cholangiocarcinoma lesions, were all observed in this cotreatment group (5). At the gene-expression level, we have shown a single down-regulated and 23 up-regulated give transcripts that were involved in Ov-induced CCA development (6). The up-regulated genes include signal 
transduction protein kinases, a transcriptional factor, a protein involved in lipid metabolism, a splicing regulatory protein, an enzyme involved in protein degradation and cell skeletal proteins (6). In addition, we demonstrated that praziquantel, an anti-helminthic drug for liver fluke treatment, can prevent $\mathrm{Ov}$ and NDMA-induced CCA in hamsters (7). However, the molecular mechanism through which praziquantel prevents the combinatory effect of $\mathrm{Ov}$ and NDMA in CCA development remains to be elucidated.

Metabolomics, one of the omics technologies in the systems biology suite, has been used to investigate the molecular mechanisms underlying the development and progression of cancer (8). The metabolic profiling of bile (9), serum (10) and urine (11) of CCA patients has been investigated. Metabolomics is defined as the quantitative and qualitative measurement of the small molecular weight metabolites of cells, tissue, or the organism (12). NMRbased metabolomics is less cost-effective and requires minimum sample preparation compared to genomics, transcriptomics and proteomics (13). The alterations in metabolic profiles can be considered as the responses of the biological system to genetic or environmental changes (14). ${ }^{1} \mathrm{H}$ Nuclear magnetic resonance (NMR) spectroscopy, gas chromatography- and liquid chromatography-mass spectrometry are the main analytical platforms used in metabolomics. In cancer research, metabolomics are used to identify potential biomarkers for early detection and diagnosis, and predictive markers for drug responses and treatment monitoring and evaluation (15). Several metabolites related to metabolic pathway alteration were identified as potential biomarkers for detection of many types of cancer, such as gastric (16), colorectal (17), breast (18), pancreatic (19), and prostatic cancer (20). Moreover, metabolomics can be used to obtain a more thorough understanding of the molecular mechanism underlying carcinogenesis (13). The metabolic profiling of bile acid in patients with CCA compared with patients with other biliary disease has been studied. It was found that altered bile acid and phosphatidylcholine metabolism might play an important role in the carcinogenesis processes of CCA (9). Moreover, the urinary metabolic profiles in CCA compared with hepatocellular carcinoma, metastatic secondary liver cancer, pancreatic cancer and ovarian cancer revealed that the levels of acylcarnitine, bile acid, and purine were significantly elevated in CCA compared with controls (11).

The present study aimed to investigate metabolic profiles during $\mathrm{Ov}$ infection in combination with NDMA administration-induced cholangiocyte transformation in the hamster model, as well as to investigate the molecular mechanism by which praziquantel may prevent $\mathrm{Ov}$ and NDMA-induced cholangiocyte transformation in the hamster CCA model. The knowledge gained from this study will benefit the prevention and control of CCA development.

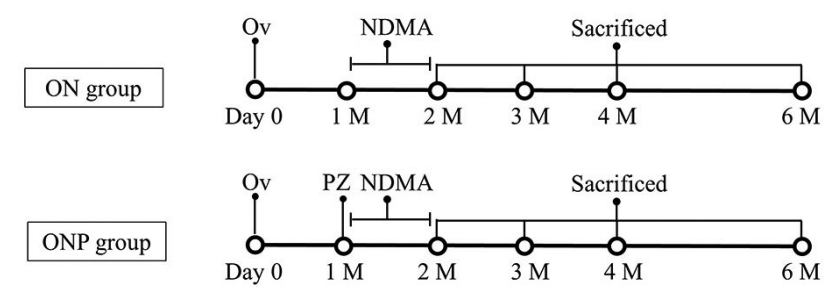

Figure 1. Experimental design of the Opisthorchis viverrini (Ov) infection in the hamster model of $N$-nitrosodimethylamine (NDMA)induced cholangiocarcinoma. ON: Ov+NDMA, ONP: Ov+NDMA+ praziquantel, PZ: praziquantel, $M$ : months.

\section{Materials and Methods}

Animal experiment. Archived liver tissues from the hamster model of Ov infection plus NDMA-induced CCA from our group's previous study were used (7). The protocol was approved by the Animal Ethics Committee, Faculty of Medicine, Khon Kaen University (approval numbers AEKKU23/2555 and IACUC-KKU61/62). Briefly, six- to eight-week-old male Syrian golden hamsters were divided into two groups: One with Ov infection and NDMA administration, and the other with Ov infection, NDMA administration and praziquantel treatment. Firstly, hamsters were treated with 50 Ov metacercaria using oral inoculation and received 12.5 ppm of NDMA (Sigma, St. Louis, MO, USA) in water, during the first to the second month after Ov infection. After that, the experimental group was treated with a single dose of $400 \mathrm{mg} / \mathrm{kg}$ praziquantel after 1 month of Ov infection. Five of the animals per group were sacrificed at 2,3,4 and 6 months after treatment and hamster liver tissues were collected for further analysis. All liver tissues were kept at $-80^{\circ} \mathrm{C}$ prior to metabolite extraction (Figure 1).

Extraction of metabolites from hamster liver tissues. The methanol/chloroform/water method previously reported was used for metabolite extraction in the current study (21). The median lobe of frozen hamster liver (100 mg per sample) was chopped and mashed. To extract the metabolites, a mixture of methanol:chloroform:water $(1: 1: 0.7)$ was added. Then the samples were left on ice for $15 \mathrm{~min}$. After that, the samples were homogenized at $40 \%$ amplitude, for $1 \mathrm{~min}$ $30 \mathrm{~s}$, at $4^{\circ} \mathrm{C}$ using a sonicator (Sonics \& Materials Inc., Newtoen, CT, USA). Next, the two-phase metabolites were separated using centrifugation at $1,000 \times g$ at $4^{\circ} \mathrm{C}$ for $15 \mathrm{~min}$. The aqueous phase was separated and evaporated at $40^{\circ} \mathrm{C}$ for $20 \mathrm{~h}$ using a speed vacuum concentrator (Labconco, Kansas City, MO, USA). The extracts were stored at $-80^{\circ} \mathrm{C}$ prior to NMR-based global metabolic profile analysis.

NMR data acquisition, data processing and data analysis. Firstly, the samples were mixed with $100 \mathrm{mM}$ sodium phosphate buffer, $\mathrm{pH} 7.4$ in $\mathrm{D}_{2} \mathrm{O}$ containing $0.1 \% \mathrm{w} / \mathrm{v}$ 3-trimethysilypropionic acid (Cambridge Isotope Laboratories, Tewksbury, MA, USA) as a chemical shift reference, and optionally $0.2 \% \mathrm{NaN}_{3}$. The mixtures were centrifuged at $12,000 \times g$ for $5 \mathrm{~min}$ and $550 \mu \mathrm{l}$ of the supernatant was transferred into a $5 \mathrm{~mm}$ NMR tube. Proton NMR spectra were acquired using a $400 \mathrm{MHz}$ NMR spectrometer (Bruker, Ettlingen, Germany). The samples were detected in a standard 1-dimension (1-D) pulse sequence as standard Bruker pulse program or zg30 pulse sequence at a temperature of $298 \mathrm{~K}$ 
in 32 scans with spectral width of $20 \mathrm{ppm}$ and $1 \mathrm{~s}$ relaxation decay $(22,23)$. The chemical shift referencing, baseline correction and phasing were conducted in TopSpin (Bruker, Germany). The NMR spectra data were processed to adjust peak normalization with probabilistic quotient normalization (24) and scaling with Pareto scaling (25) in MATLAB (R2015a) environment (MathWorks, Cambridge, UK). Next, the differences between samples were investigated using multivariate statistical analysis, PCA and OPLS-DA, and the correlation between metabolic profiles and the histopathological results were investigated using O-PLS regression $(26,27)$. The correlated resonances of each metabolite was identified using Statistical Total Correlation Spectroscopy (STOCSY) and metabolite identification was performed using the human metabolome database (HMDB) (http://www.hmdb.ca) and Chenomx NMR suite v. 8.4 (Chenomx Inc., Alberta, Canada). All candidate metabolites were selected for network analysis with the Cricetulus griseus database using the MetaboNetworks tool in the MATLAB environment (28). The candidate metabolites were selected and used for further functional analysis using the U937 macrophage cell line as the model.

Hematoxylin and eosin staining. Hematoxylin and eosin (H\&E) staining was performed as previously described (7). Briefly, hamster liver tissues were sectioned, then fixed in $10 \%$ buffered formaldehyde and embedded in paraffin. The sectioned tissues were deparaffinized in xylene for $3 \mathrm{~min}$, three times, and then rehydrated in a dilution series of ethanol. The sectioned tissues were rinsed with tap water and stained with Harr's hematoxylin for 10 min and then washed with running tap water for 2 min. Then, the stained tissue sections were de-stained in ethanol containing $1 \%$ hydrochloric acid. They were then washed with running tap water and stained in saturated lithium carbonate for 3-4 s. After that, the sectioned tissues were washed with tap water, stained with eosin solution and dehydrated. The dehydrated tissue sections were mounted with permount. Finally, the histopathological changes in hamster liver tissue were observed under the microscope.

Histopathological grading. The histopathological features of hamster liver tissues were graded as a percentage score by a pathologist. The histological criteria were characterized into frequency of inflammation ( 0 , no inflammation; 1 , mild (5-20\% per $4 \times$ objective), 2 , moderate (20-50\% per $4 \times$ objective), 3 , severe $(>50 \%$ per $4 \times$ objective), percent of severity of bile duct alteration (normal area, hyperplasia, dysplasia and CCA area), and percentage of fibrosis ( 0 , no fibrosis; 1 , portal fibrosis without short fibrous septa; 2, portal fibrosis with short fibrous septa; 3 , portal fibrosis with fibrous septa) (29). The scores for the percentage of bile duct alteration and fibrosis, as well as the frequency of inflammation, were multiplied. The association between the histopathological features was correlated with the metabolomics result using O-PLSregression analysis.

Human U937 macrophage cell culture. The human U937 macrophage cell line is commonly used as the model for an IL6 production and inhibition assay (30-32). The cell line was obtained from the American Type Culture Collection and was cultured in RPMI 1640 medium (Gibco Life Technology, Grand Island, NY, USA) supplemented with $10 \%$ heat-inactivated fetal bovine serum, $100 \mathrm{U} / \mathrm{ml}$ penicillin and $100 \mu \mathrm{g} / \mathrm{ml}$ streptomycin at $37^{\circ} \mathrm{C}$ in a humidified incubator with $5 \% \mathrm{CO}_{2}$.
Cell treatment. Macrophage cells were seeded in 6-well plates $\left(2.5 \times 10^{5}\right.$ cells/well) for 24 hours. The cells were treated with a combination of the candidate metabolites at different concentrations, including sarcosine; $0,5,10,15,20,25 \mu \mathrm{M}$, inosine; $0,100,200,400,800,1,000$ $\mu \mathrm{M}$ and sodium acetate; $0,100,200,400,800,1,000 \mu \mathrm{M}$, respectively, for $48 \mathrm{~h}$ at $37^{\circ} \mathrm{C}$ in a humidified atmosphere with $5 \% \mathrm{CO}_{2}$. The cell pellet was collected for investigating the expression of interleukin-6 (IL6) by western blot analysis. The cultured media were collected for investigating of the IL6 level using the ELISA technique. The cell treatment was performed in three independent experiments.

Western blot analysis. Cells were lysed through the addition of $10 \%$ NP-40 lysis buffer containing a protease $\mathrm{K}$ inhibitor cocktail. Then, the cell lysate was centrifuged at $12,000 \mathrm{rpm}$ for $10 \mathrm{~min}$ at $4^{\circ} \mathrm{C}$ followed by transferring the supernatant to a new $1.5 \mathrm{~mL}$ tube. The concentration of total protein was determined using a Pierce $\mathrm{BCA}^{\mathrm{TM}}$ Protein Assay Kit (Thermo Fisher Scientific, Hanover Park, IL, USA). Then, the protein lysate was mixed with $4 \times$ sodium dodecyl sulphate buffer containing dithiothreitol before being denatured at $95^{\circ} \mathrm{C}$ for $5 \mathrm{~min}$. Fifteen micrograms of protein were electrophoresed by $12 \%(\mathrm{w} / \mathrm{v})$ sodium dodecyl sulfate-polyacrylamide gel and transferred to a polyvinylidene fluoride membrane. Then, the membranes were blocked with 5\% skim milk plus tween for 1 hour at room temperature followed by incubation with the primary antibody overnight at $4^{\circ} \mathrm{C}$. After that, the membranes were shaken at room temperature for 1 hour, followed by washing with tris-buffered saline containing $0.1 \%$ Tween 203 times for $5 \mathrm{~min}$. Next, the membranes were probed with secondary antibody for 1 hour at room temperature, washed and the immunoreactive materials detected using Enhanced Chemiluminescence Plus solution (GE Healthcare, Buckinghamshire, UK). In this study, $\beta$-actin antibody was used as an internal loading control for cytoplasm. The apparent density of the bands on the membranes was captured by ImageJ software (NIH, Bethesda, MD, USA).

Enzyme-linked immunosorbent assay (ELISA). The IL6 secreted by the macrophage cell line in the culture medium was detected using commercial ELISA kits (R\&D System, Minneapolis, MN, USA) according to the manufacturer's instructions. Briefly, $100 \mu \mathrm{l}$ of cultured medium were incubated in pre-coated 96-well plates for 2 $\mathrm{h}$. The plates were then washed four times with washing buffer followed by incubation with human IL6 conjugate for $2 \mathrm{~h}$. After four washes, the substrate solution was added and the plates incubated for $20 \mathrm{~min}$ in the dark before the stop solution was added. The level of IL6 was determined at $450 \mathrm{~nm}$ using a Tecan Sunrise ELISA Reader (Triad Scientific, Manasquan, NJ, USA).

Univariate statistical analysis. The maximum intensities as relative concentrations of each metabolite were analyzed by Mann-Whitney $U$-test. The histopathological score, level of protein expression in the western blot analysis and ELISA were analyzed by Student's $t$-test using SPSS software version 17 (IBM Corporation, Armonk, NY, USA). The data are illustrated as a graph of the mean \pm SD using Graph Pad prism 5 (GraphPad Software, Inc., San Diego, CA, USA). All of the analyses were two-tailed and a p-value of less than 0.05 was considered as statistically significant.

\section{Results}

Histopathological changes. The hamsters were infected with Ov and administered NDMA prior to random grouping into 
A 2 Months

3 Months

4 Months

6 Months

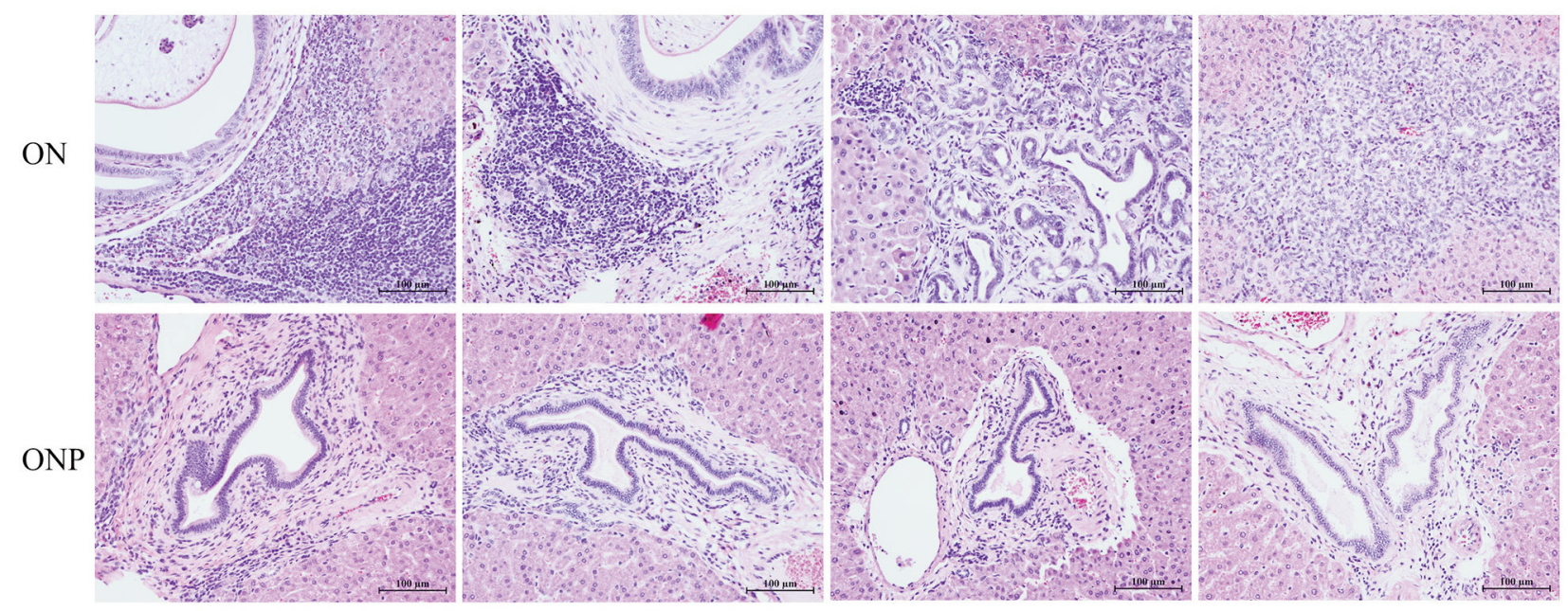

B
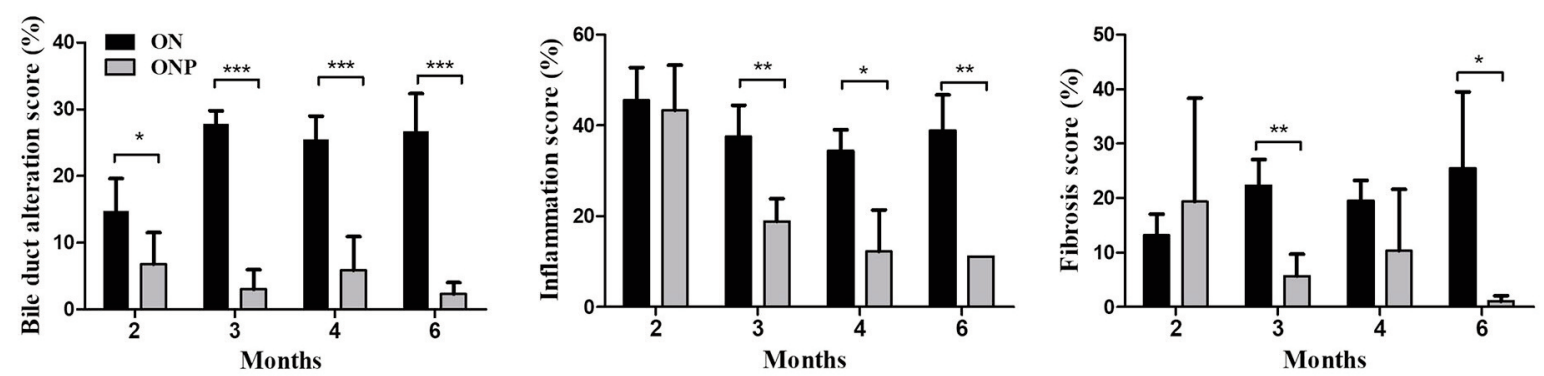

Figure 2. Histopathological changes in hamster liver tissues. A: Representative images of histological changes in hamsters with Opisthorchis viverrini and $N$-nitrosodimethylamine-induced cholangiocarcinoma treated with (ONP) and without praziquantel (ON). B: Bile duct alteration, inflammation and fibrosis scores of the ON and ONP groups. Significantly different at *p<0.05, **p<0.01 and ***p<0.001, respectively, using Student's t-test.

either praziquantel-treated or non-treated groups, as shown in Figure 1. Five animals from each group were culled at each time point for histopathological examination of the liver tissues. The histopathological changes of the hamster bile duct tissues obtained from the untreated group revealed both hyperplasia and dysplasia of the bile duct epithelia throughout the study period at 2,3,4 and 6 months. One of five hamsters in this group $(1 / 5,20 \%)$, exhibited CCA at 6 months. In contrast, the most severe pathological appearance observed in the praziquantel-treated group over the 6-month period was bile duct hyperplasia, while no dysplasia was observed. Although one of the hamsters $(1 / 5,20 \%)$ exhibited CCA at 4 months, the other animals did not develop CCA (Figure 2A). The percentages of bile duct change, inflammation and fibrosis scores were lower in the praziquantel-treated group compared to the untreated group (Figure 2B). These results indicate that praziquantel was able to suppress the severity of the Ov and NDMA-induced histopathological changes in the bile duct.

Metabolic profiling of praziquantel-mediated prevention of Ov and NDMA-induced CCA in a hamster model. Metabolic profiling of hamster liver tissues was determined using 400 $\mathrm{MHz}{ }^{1} \mathrm{H}-\mathrm{NMR}$ spectroscopy-based metabolomics. The proton NMR spectra were analyzed using multivariate statistics, including unsupervised principal component analysis (PCA) and supervised orthogonal partial least squares analysis (O-PLS-DA). The PCA scores plot of the model between the two groups demonstrated a clear separation along the second principal component (PC2) $\left(\mathrm{Q}^{2}=0.68, \mathrm{R}^{2} ; \mathrm{PC} 1=60.1 \%, \mathrm{PC} 2=7.4 \%\right)$ (Figure $\left.3 \mathrm{~A}\right)$. PCA was also carried out based on each time point (Figure 3B-E) and, as time progressed, the clustering between the treated and untreated with groups became clearer. 
A

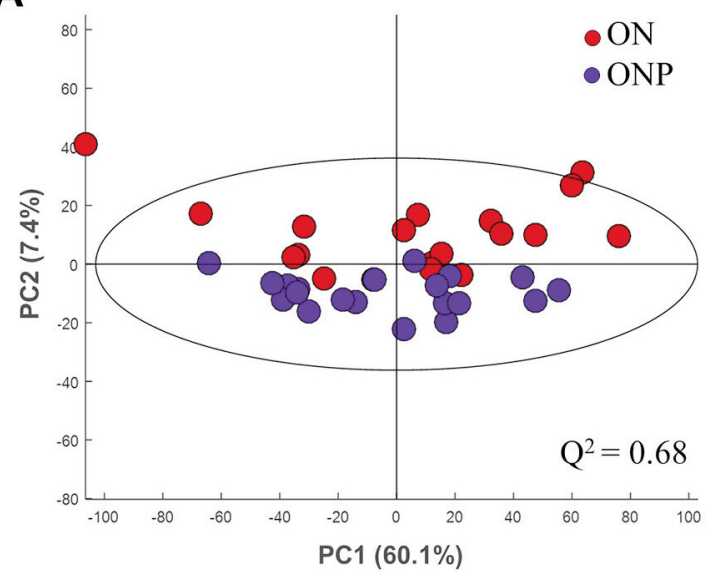

B

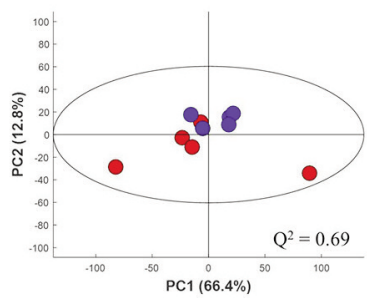

D

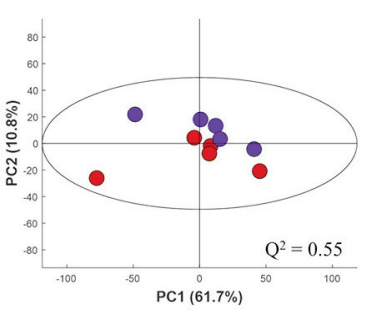

C

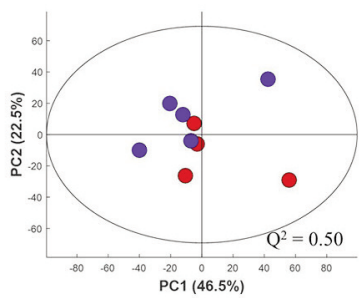

E

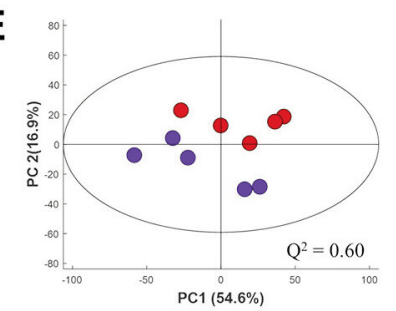

Figure 3. Principal component analysis (PCA) score plots for liver tissues from untreated (ON; red) and praziquantel-treated (ONP; blue) hamsters with N-nitrosodimethylamine-induced cholangiocarcinoma for all months (A), and at (B) 2 months, (C) 3 months, (D) 4 months and (E) 6 months. $Q^{2}$ represents the predictive ability of the model. The percentage on each PC represents the variance explained by each.

A

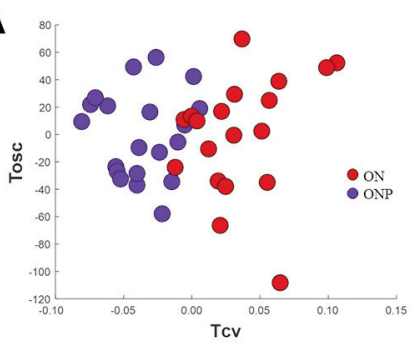

B

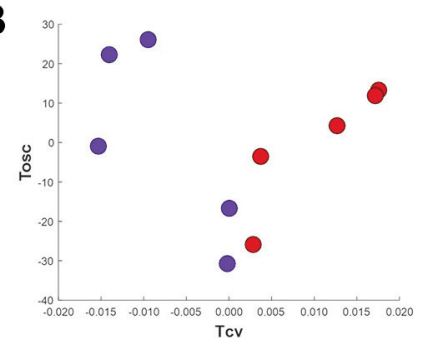

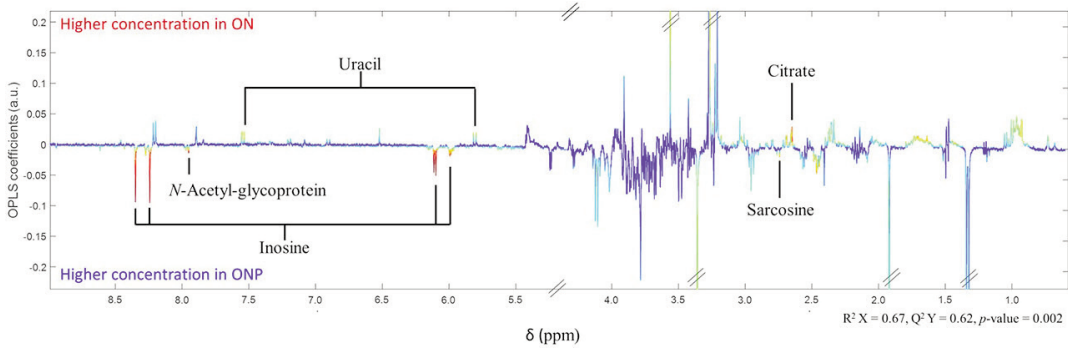

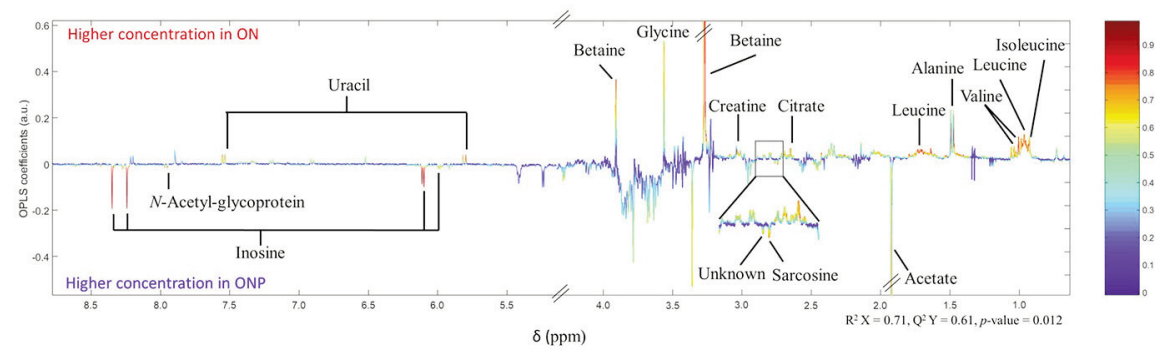

Figure 4. Orthogonal partial least squares discriminant analysis (O-PLS-DA) cross-validated score plot (left) and the loading plot (right) for hamster liver tissues. The O-PLS-DA cross-validated score plot and the O-PLS-DA loading plot demonstrate the significant metabolites contributing to the separation between hamsters with Opisthorchis viverrini and $N$-nitrosodimethylamine-induced cholangiocarcinoma treated with $(O N P)$ and without praziquantel $(O N)$ considering all months $(A)$ and at 6 months $(B)$, respectively. Peaks pointing upwards represent relatively high levels of metabolites in the ON group, whereas peaks pointing downwards represent relative low levels of metabolites in the ON group. Tosc: T orthogonal signal correction; Tcv: T cross validation.

In order to further investigate the significantly altered liver biomarkers between the praziquantel-treated and untreated groups, pairwise O-PLS-DA models for the different time points were constructed. The cross-validated scores plots provide a visualization of the separation between the two groups and the loadings plots show the significant metabolites contributing to the separation. Significant differences between the groups with all the time points combined were observed (Figure 4A, left; $R^{2} X=0.67$, $\left.\mathrm{Q}^{2} \mathrm{Y}=0.62, p=0.002\right)$. The praziquantel-treated group showed 
Table I. The summary of metabolic changes in liver tissues from untreated (ON) and praziquantel-treated (ONP) hamsters with $N$ nitrosodimethylamine-induced cholangiocarcinoma.

\begin{tabular}{|c|c|c|c|c|c|c|}
\hline \multirow[t]{2}{*}{ Metabolite } & \multirow{2}{*}{$\begin{array}{c}\text { Chemical } \\
\text { shift }\end{array}$} & \multicolumn{5}{|c|}{ O-PLS model } \\
\hline & & $\begin{array}{c}\text { ON vs. ONP } \\
\text { (permutation } \\
p=0.002 \text { ) }\end{array}$ & $\begin{array}{c}\text { At } 6 \text { months } \\
\text { ON vs. ONP } \\
\text { (permutation } \\
p=0.012 \text { ) }\end{array}$ & $\begin{array}{c}\text { Bile duct } \\
\text { severity } \\
\text { (permutation } \\
p=0.001 \text { ) }\end{array}$ & $\begin{array}{l}\text { Inflammation } \\
\text { (permutation } \\
p=0.003 \text { ) }\end{array}$ & $\begin{array}{c}\begin{array}{c}\text { Fibrosis } \\
\text { (permutation } \\
p=0.020 \text { ) }\end{array}\end{array}$ \\
\hline Acetate & $1.92(\mathrm{~s})$ & & $-0.774 *$ & & & \\
\hline Alanine & $1.48(\mathrm{~d}) ; 3.79(\mathrm{q})$ & & +0.6829 & & & \\
\hline Betaine & $3.27(\mathrm{~s}) ; 3.9(\mathrm{~s})$ & & +0.8859 & & & \\
\hline Citrate & $2.66(\mathrm{~d})$ & $+0.6946^{* * *}$ & $+0.8275^{*}$ & & & \\
\hline Creatine & $3.04(\mathrm{~s}) ; 3.93(\mathrm{~s})$ & & +0.6574 & & & \\
\hline Glycine & $3.57(\mathrm{~s})$ & & $+0.8017 * *$ & & & \\
\hline Inosine & $6.1(\mathrm{~d}) ; 8.24(\mathrm{~s}) ; 8.34(\mathrm{~s})$ & $-0.7805^{* * *}$ & $-0.9703 * *$ & -0.7532 & & \\
\hline Isoleucine & $\begin{array}{l}0.94(\mathrm{t}) ; 1.01(\mathrm{~d}) ; 1.26(\mathrm{~m}) \\
1.48(\mathrm{~m}) ; 1.98(\mathrm{~m}) ; 3.68(\mathrm{~d})\end{array}$ & & $+0.8677 * *$ & & & \\
\hline Leucine & $0.96(\mathrm{t}) ; 1.71(\mathrm{~m}) ; 3.73(\mathrm{t})$ & & $+0.9264^{* *}$ & & & \\
\hline$N$-Acetyl-glycoprotein & $7.95(d)$ & $-0.7593 * * *$ & $-0.8446^{* *}$ & -0.655 & & \\
\hline Sarcosine & $2.74(\mathrm{~s}) ; 3.61(\mathrm{~s})$ & $-0.6701 * * *$ & $-0.8547 * *$ & -0.687 & -0.6152 & -0.6312 \\
\hline Unknown & $2.761(\mathrm{~s})$ & $-0.6701 * *$ & $-0.8404^{*}$ & & & \\
\hline Uracil & $5.81(\mathrm{~d}) ; 7.54(\mathrm{~d})$ & $+0.5941 * * *$ & $+0.9033 * *$ & & & \\
\hline Valine & $0.99(\mathrm{~d}) ; 1.04(\mathrm{~d}) ; 3.62(\mathrm{~d})$ & & $+0.8486^{*}$ & & & \\
\hline
\end{tabular}

Significantly different at $* p<0.05, * * p<0.01$ and $* * * p<0.001$, respectively.

higher concentrations of inosine, $N$-acetyl-glycoprotein, an unknown peak at $2.761 \mathrm{ppm}$ (UN1) and lower levels of citrate compared to the untreated group (Figure 4A, right). In addition, pairwise O-PLS-DA analyses of the groups at each time point were performed. A statistically significant model based on samples collected at 6 months post treatment was obtained (Figure 4B, left; $R^{2} X=0.71, Q^{2} Y=0.61$, $p=0.020)$ with the O-PLS-DA loadings plot demonstrating higher levels of acetate, inosine, $\mathrm{N}$-acetyl-glycoprotein, sarcosine and UN1 in the ONP group, together with lower levels of alanine, citrate, creatine, betaine, glycine, isoleucine, leucine, valine, uracil and valine (Figure 4, right). However, no significant metabolic alteration was detected at the other time points $(p>0.05)$.

The relative concentrations of the significantly changed metabolites were analyzed using univariate statistical methods. Higher relative concentrations of inosine, $\mathrm{N}$-acetyl-glycoprotein, sarcosine and UN1 and lower relative concentrations of citrate and uracil were observed in the praziquantel-treated group compared with the untreated group (Figure 5A). Moreover, the relative concentrations of acetate, inosine, $\mathrm{N}$-acetylglycoprotein, sarcosine and UN1, the unknown peak $\left(\delta^{1} \mathrm{H}\right.$ 2.761 ) in the praziquantel-treated group, at 6 months were significantly higher than those in the untreated group, whereas the relative concentrations of citrate, glycine, isoleucine, leucine, valine, uracil and valine were lower (Figure 5B). The chemical shifts with multiplicities of all identified metabolites are listed in Table I.
Correlation of metabolic profiles and histopathological changes. The correlations between the metabolic profiles and histopathological scores, including the severity of bile duct changes, inflammation and fibrosis, were carried out using O-PLS regression analysis. The metabolic profiles of the hamster liver tissues were significantly positively correlated with bile duct changes, inflammation and fibrosis ( $p=0.001$, 0.003 and 0.02 , respectively). The O-PLS regression loading plot demonstrated that $\mathrm{N}$-acetlyl-glycoprotein, inosine and sarcosine levels were negatively correlated with the severity of bile duct changes. Furthermore, the concentration of sarcosine was also negatively correlated with tissue inflammation and fibrosis scores (Figure 6).

Biological network analysis of the Ov and NDMA-treated and praziquantel-treated CCA-bearing hamster groups. The significant metabolites from all models, alanine, betaine, citrate, creatine, glycine, inosine, isoleucine, leucine, sarcosine, uracil and valine, were selected for the biological network analysis using the MetaboNetworks (28), a tool to create sub-networks from the main reaction based on the Kyoto Encyclopedia of Genes and Genomes. It calculates the shortest pathway between a set of metabolites, then plots the connectivity between them and links in a network graph. The main altered pathways include amino acid metabolism, branch-chain amino acid metabolism, choline and betaine metabolism, glutathione metabolism, glycine and serine metabolism, lipid and fatty acid metabolism, purine 
A
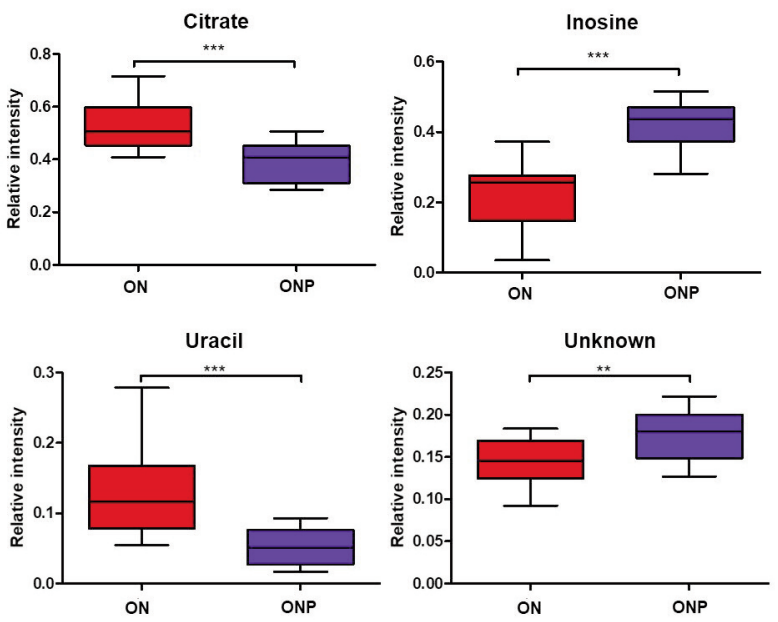

B
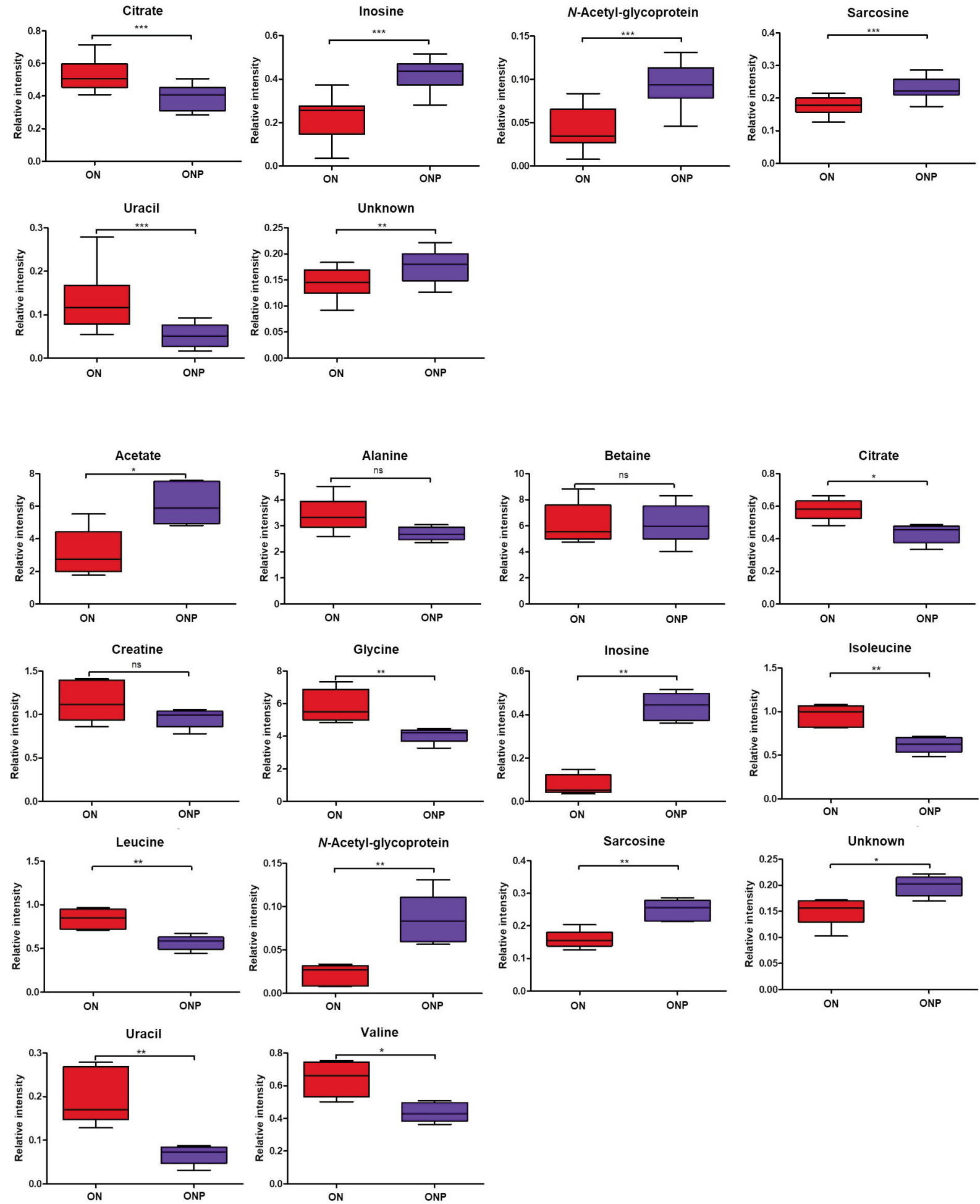

Figure 5. The relative concentrations of significantly changed metabolites in liver tissues from untreated (ON) and praziquantel-treated (ONP) hamsters with $\mathrm{N}$-nitrosodimethylamine-induced cholangiocarcinoma. The maximum intensities of the significant metabolites from multivariate statistics were analyzed by univariate statistics from entire model (A) and that for 6 months (B). Significantly different at * $p<0.05$, ** $p<0.01$ and $* * * p<0.001$, respectively. 
A

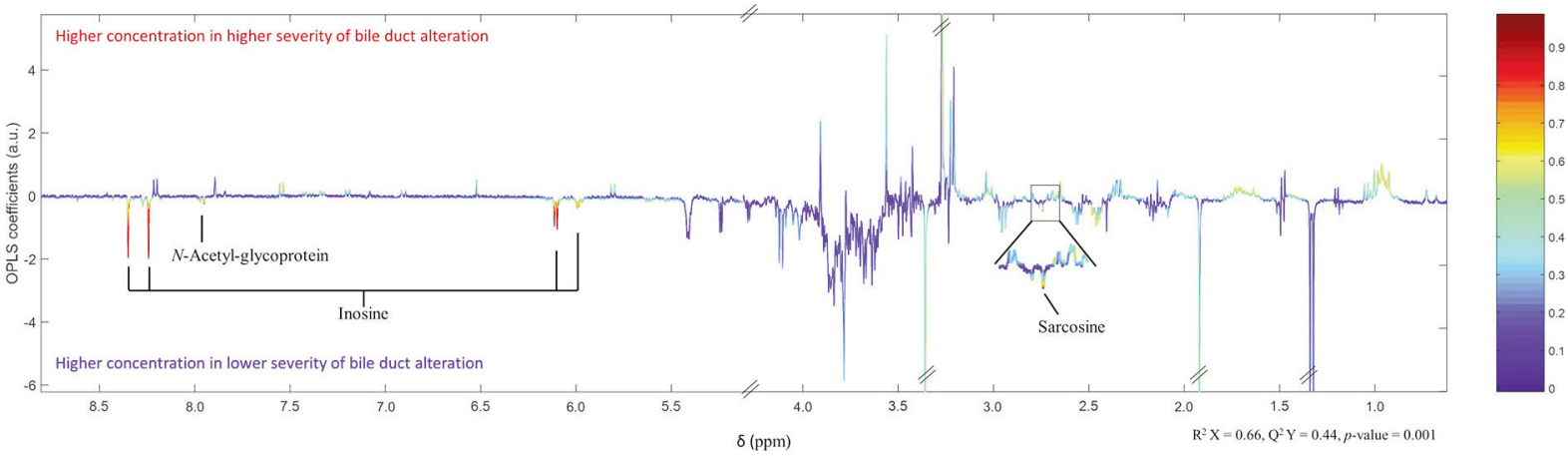

B

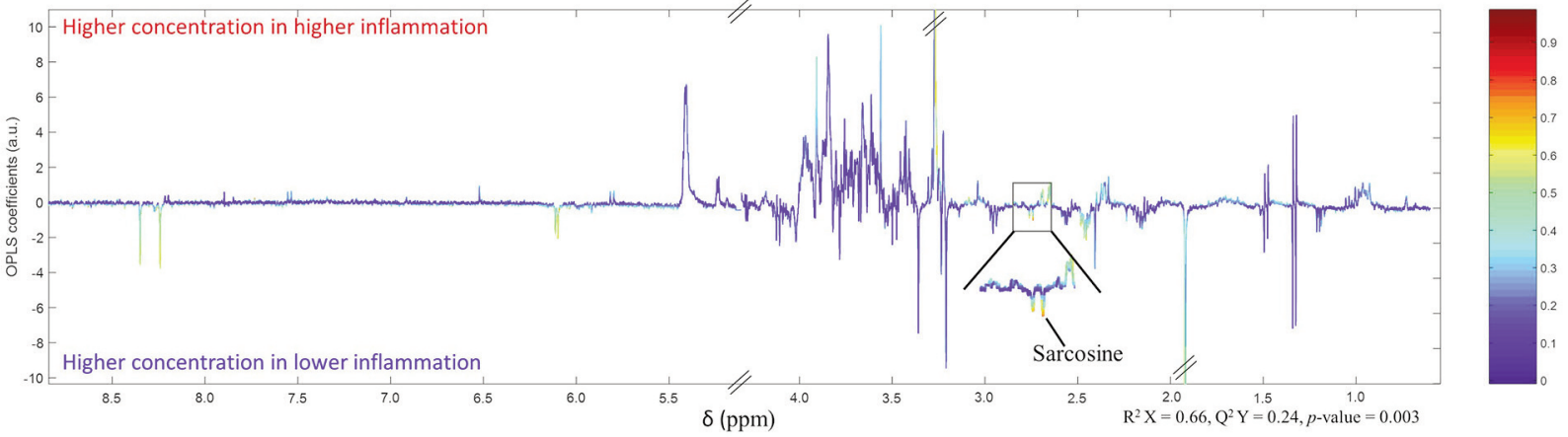

C

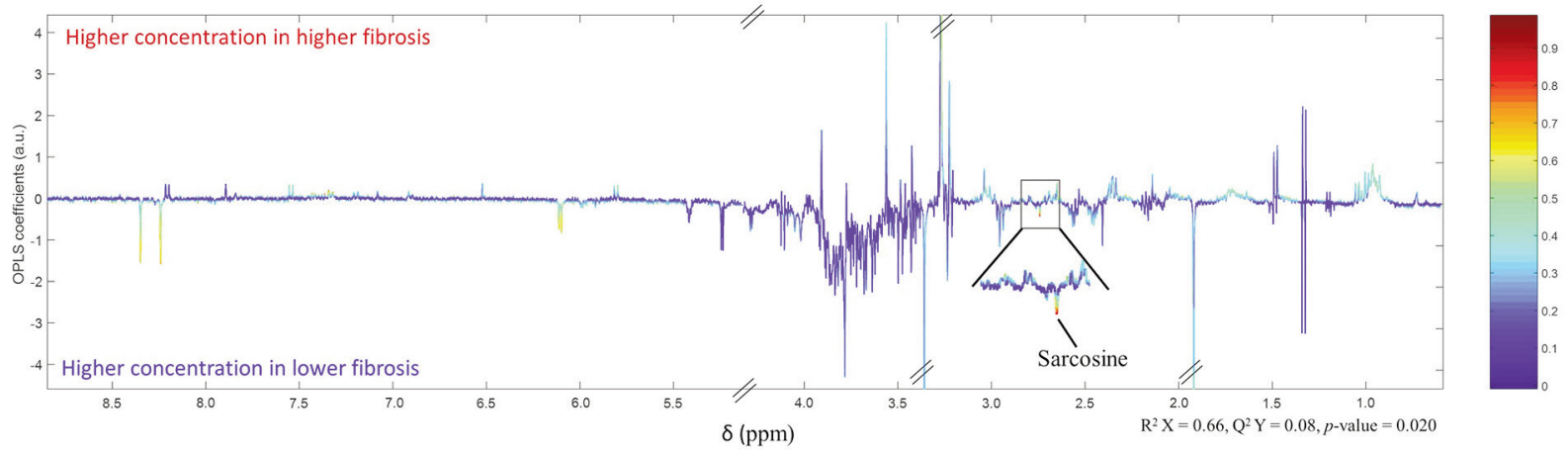

Figure 6. Orthogonal partial least squares (O-PLS)-regression analysis. O-PLS-regression loading plot of the histopathological results, including severity of bile duct alteration (A), inflammation (B) and fibrosis (C).

metabolism, pyrimidine metabolism, pyruvate metabolism, tricarboxylic acid (TCA) metabolism, TCA anaplerotic metabolism and the urea cycle (Figure 7).

The anti-inflammatory effect of inosine, sarcosine and acetate and their combination on the prevention of CCA development. Increasing levels of inosine, sarcosine and acetate were found in the ONP group. Interestingly, an antiinflammatory property of inosine and acetate was identified in previous studies $(33,34)$. Moreover, our result demonstrates that the sarcosine level was negatively correlated with inflammation. Therefore, we further investigated the anti-inflammatory effect of inosine, sarcosine and acetate for the prevention of CCA development. An absolute concentration of these metabolites was calculated from their maximum intensity compared to the maximum intensity of the 3-(trimethylsilyl)-2,2,3,3tetradeuteropropionic acid peak. The U937 macrophage cell line was treated for $48 \mathrm{~h}$ with an absolute concentration of each metabolite or a combination of the three metabolites. Then, the expression of IL6 in treated and untreated cells was investigated using western blot analysis. The combined treatment condition significantly reduced the expression of IL6 at $48 \mathrm{~h}$ (Figure 8A and B). The IL6 levels in the culture medium after combined metabolite treatment was measured using ELISA. We observed that IL6 significantly decreased 


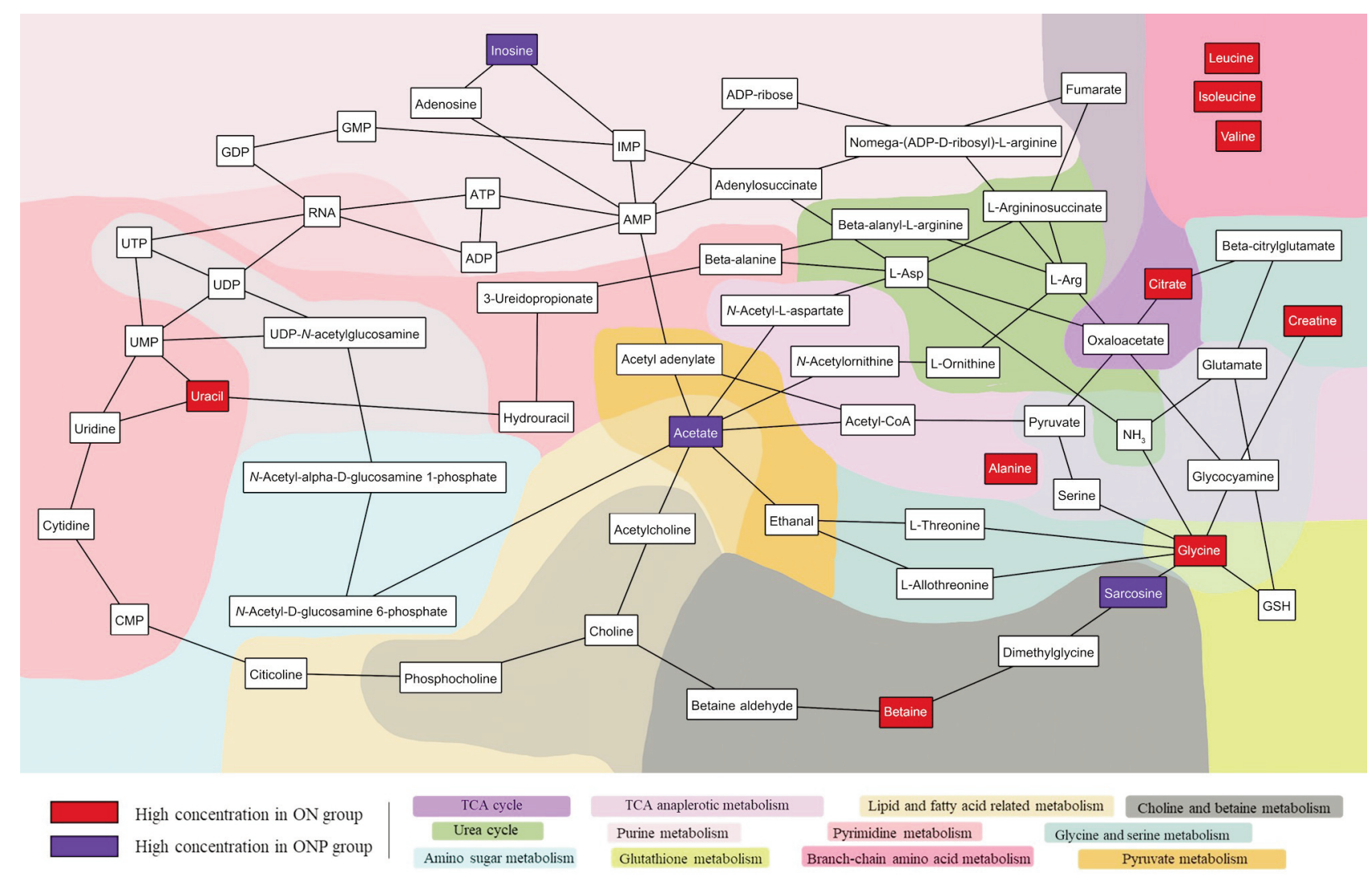

Figure 7. A biological network analysis of metabolic profiling of hamster liver tissues. All significant metabolites were mapped onto the Kyoto Encyclopedia of Genes and Genomes (KEGG) database for the biological network analysis using MetaboNetworks software.

following $48 \mathrm{~h}$ of treatment (Figure $8 \mathrm{C}$ ). These results collectively indicated the combinatory anti-inflammatory effects of inosine, sarcosine and acetate on the inhibition of IL6 production in the macrophage cell line.

\section{Discussion}

The strategies for CCA prevention and treatment are still ineffective. One of the best potential strategies for CCA prevention is praziquantel administration. Praziquantel is an anti-helminthic drug that has been used for Ov elimination (35). Current reports suggested that praziquantel treatment can prevent CCA development in the CCA-induced hamster model (7). This is in accordance with a previous study which demonstrated that liver fibrosis and egg granulomatosis observed in hamster liver tissues with liver fluke infection were reduced after praziquantel treatment (36). Similarly, this study indicates that praziquantel can suppress the severity of Ov and NDMA-induced CCA development despite the fact that one hamster had CCA after praziquantel treatment. Praziquantel is an effective therapy, with the cure rate for opisthorchiasis being $95 \%$ in hamsters with a single $400 \mathrm{mg} / \mathrm{kg}$ oral dose (37), $71.4 \%$ with a $40 \mathrm{mg} / \mathrm{kg}$ standard single dose and $96.6 \%$ with a $75 \mathrm{mg} / \mathrm{kg}$ total dose in school children (38).

In cancer cells, central metabolism reprogramming is the enhancement of glycolysis in order to support rapid cell proliferation $(39,40)$. TCA intermediates are also used as precursors for fundamental cellular biomolecule synthesis (41). Cancer cells require carbon atoms from the TCA anaplerotic pathway to supply the TCA cycle. The present study demonstrated increasing levels of citrate and the intermediate molecules in the TCA cycle in the praziquanteltreated group at 6 months. The oxidation of the branch-chain amino acids alanine and serine can be a source of carbon for the anaplerotic flux as they are converted to TCA cycle intermediates to support the glycolytic flux (42). Our study also demonstrated that the increased levels of the six amino acids, leucine, isoleucine, valine, alanine, glycine, and serine, in the praziquantel-treated group may support an increased glycolytic flux which conforms with the needs for up- 


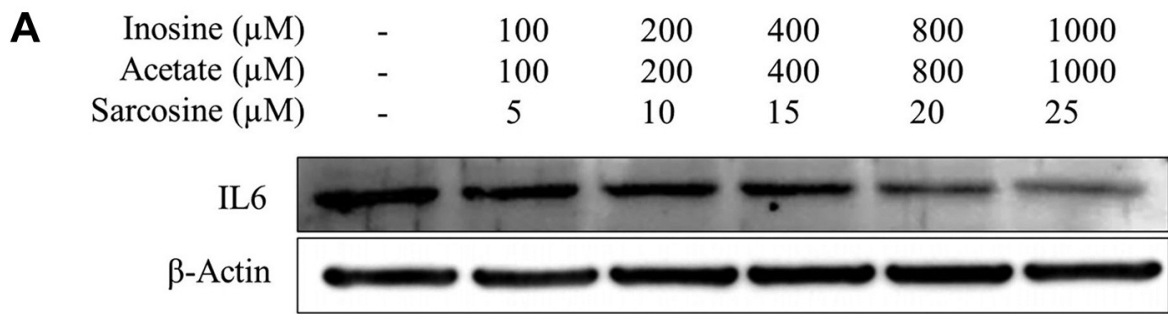

B

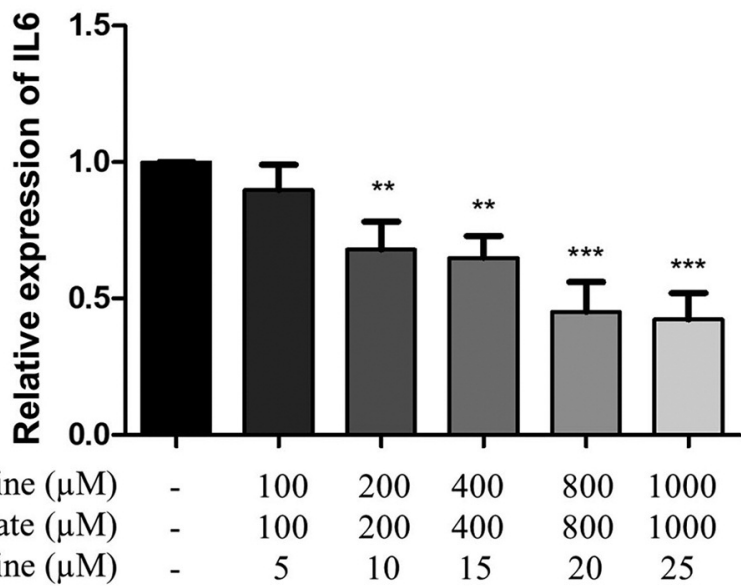

C

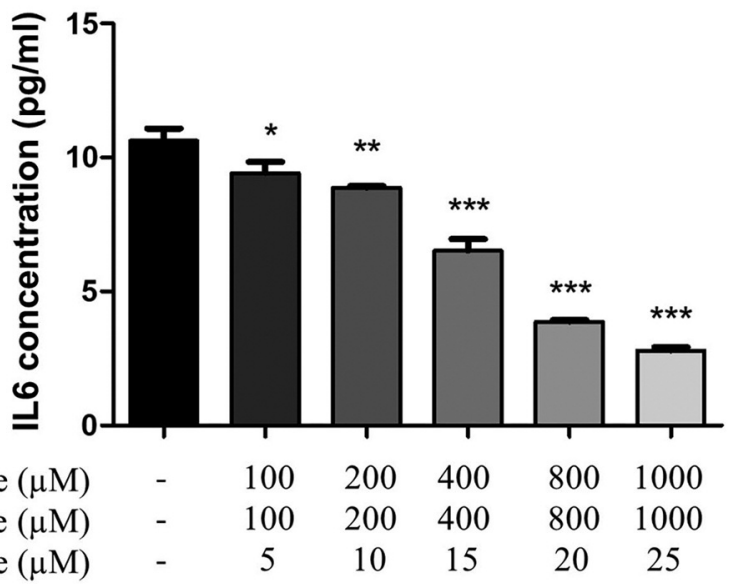

Figure 8. The anti-inflammatory effect of a combination of inosine, sarcosine and acetate on the prevention of cholangiocarcinoma development. A: Western blot analysis demonstrated the reduction of expression of interleukin-6 (IL6) after treatment with the combined metabolites in the U937 macrophage cell line. B: Relative expression level of IL6 after treatment with the combined metabolites in macrophage cells. C: IL6 level in culture media after treatment with combined metabolites. Significantly different at $* p<0.05, * * p<0.01$ and $* * * p<0.001$, respectively, using Student's $t$-test.

regulation of protein synthesis in cancer cells. A previous report demonstrated that an increased glycine level from altered glycolysis is associated with a poor prognosis in patients with breast cancer (43). Moreover, increasing levels of leucine and isoleucine can activate the mammalian target of rapamycin signaling pathway, resulting in enhanced cell growth in pancreatic cancer cells (44).
Up-regulation choline metabolism has been investigated in cancer, demonstrating that choline is used for phosphocholine synthesis or oxidized to betaine, resulting in a low concentration of choline and high concentrations of phosphocholine and betaine (45). In this study, the betaine level was increased in the untreated group. The increases in choline and betaine levels may serve as providing greater 
concentrations of methyl group donors, which may affect carcinogenesis through the influence of methylation and the synthesis of DNA (46). Furthermore, an increased creatine level was observed in the untreated group, which corresponds to previous studies showing that increased creatine levels in lung cancer tissues (47) and in urine of patients with hepatocellular carcinoma (48). Creatine functions in cellular energy transport and interacts with adenosine triphosphate to form phosphocreatine and adenosine diphosphate (48). Creatine synthesis requires three amino acids including methionine, glycine, and arginine. In the liver, guanidinoacetate acid, a product from arginine and glycine, is methylated to produce creatine (49). Therefore, high levels of creatine may be a result of high levels of glycine and serine metabolism, as shown in the biological network.

The uracil level was found to be increased in the untreated group. Uracil serves as the precursor in ribonucleic acid and is a basic unit in protein structure. The breakdown of pyrimidines provides malonyl-S-CoA and methylmalonyl-SCoA, which enters the TCA cycle (50). An increased level of uracil might reflect the rapid proliferation of cancer cells. Furthermore, high levels of uracil were reported in gastric cancer tissues, which similarly suggests the state of rapid growth and proliferation of cancer cells (16).

Our study also demonstrated increased levels of acetate, sarcosine, and inosine in liver tissues from hamsters treated with praziquantel. Acetate, a salt of acetic acid, is produced by bacterial fermentation in the intestines, alcohol metabolism, and the endogenous metabolism of cellular components, such as long-chain fatty acids (51). Increased levels of acetate and inosine/adenosine have been reported in lung tissues compared with adjacent lung cancer tissues (47). Moreover, the acetate level was found to be reduced in the urine of patients with prostate cancer (52) in whom acetate might be used by cancer cells as a source of lipid biosynthesis in tumors (53). Moreover, the acetate level was found to be reduced in the feces of patients with colorectal cancer, which was caused by a disturbance of the intestinal microbiota and host tissues associated with colorectal tumorigenesis (17). In addition, acetate treatment significantly suppressed histone deacetylase activity and enhanced global histone acetylation in human macrophages, corresponding to a decrease in inflammatory cytokines, including IL6, IL8, and tumor necrosis factor- $\alpha$ production (54). Inosine is an endogenous purine nucleoside, which is formed during the degradation of adenosine through adenosine deaminase activity. A high concentration of inosine was found in inflamed tissues or under ischemic conditions (55). The deamination of inosine provides hypoxanthine, which is further oxidized to uric acid through the enzyme xanthine oxidoreductase. An association of xanthine oxidoreductase expression and oxidative stress, cancer aggressiveness, and poor clinical outcome has been reported (56). A previous study suggested that purine metabolites in the urine of patients with CCA showed increased levels of uric acid and 7-methylguanine, and reduced levels of hypoxanthine compared with a control group (11). In the present study, the higher levels of inosine in the praziquantel-treated group were negatively correlated with inflammation. Another study showed the anti-inflammatory effect of inosine on peritoneal macrophages that was able to inhibit the overproduction of proinflammatory cytokines while enhancing the production of protective cytokines (57). In addition, an anti-inflammatory effect of inosine in human monocytes, neutrophils, and epithelial cells has been reported (33). A decreased concentration of sarcosine in the $\mathrm{ON}$ group was observed in the present study. Sarcosine or $N$-methylglycine is an intermediate and byproduct in the synthesis and degradation of glycine. Sarcosine is formed from the methylation of glycine through $N$-methyltransferase (GNMT) activity and can be converted back into glycine via the oxidative demethylation of S-adenosylmethionine (58). In patients with CCA, 18.2\% of CCA tissues showed no expression of GNMT, whereas a higher expression level of GNMT in epithelial cells was observed in normal bile duct cells (59). A biological network showed the shortest link between the increase of glycine and reduction of sarcosine in the praziquantel-treated group, suggesting that the decrease of sarcosine may be caused by reduced demethylation of glycine. Our results also found a negative correlation between sarcosine and the severity of bile duct change, inflammation, and fibrosis.

Chronic inflammation after liver fluke infection has clearly been demonstrated to be involved in CCA carcinogenesis (60-62). During inflammation, there is an overexpression of inflammatory cytokines, especially IL6, which can promote tumor growth by inducing signal transduction and activation of the transcription of protein expression, resulting in CCA carcinogenesis and progression (63). IL6 can also up-regulate myeloid cell leukemia-1. It is an anti-apoptotic B-cell lymphoma/leukemia 2 family member protein leading to cell death resistance (64). Techasen and co-workers reported that the cytokines secreted by activated macrophages, including IL4, IL6, IL10, tumor necrosis factor- $\alpha$, and transforming growth factor $\beta 1$, can induce epithelial-mesenchymal transition through the altered expression of epithelial-mesenchymal transition -related genes in CCA (30). In the current study, we report for the first time, the anti-inflammatory effect of combined acetate, inosine, and sarcosine treatment on a macrophage cell line. The combination of acetate, inosine, and sarcosine can inhibit the production of IL6, which is a proinflammatory cytokine that plays an important role in CCA carcinogenesis.

\section{Conclusion}

Collectively, our data indicate that praziquantel can suppress the severity of Ov and NDMA-induced CCA development. The 
${ }^{1} \mathrm{H}-\mathrm{NMR}$ metabolomics results revealed that nine metabolites were significantly increased and five metabolites were significantly reduced in the praziquantel-treated group, which may phenotypically reflect CCA carcinogenesis. In addition, we also demonstrated that the combination of acetate, inosine and sarcosine exerted an anti-inflammatory effect through the inhibition of IL6 production in a macrophage cell line, which underlies the mechanism of praziquantel in preventing Ov and NDMA-induced cholangiocyte transformation and CCA development in this hamster model.

\section{Conflicts of Interest}

The Authors declare no conflicts of interest.

\section{Authors' Contributions}

Conceptualization: WL. Data curation: PP, WL. Formal analysis: PP, JP, WL. Investigation: PP. Methodology: PP, MT, PS, HD, YK. Project administration: WL. Software: JP. Supervision: WL. Validation: WL. Writing - original draft: PP, WL. Writing - review \& editing: PP, JP, NN, PK, PS, MT, HD, YK, JVL, WL.

\section{Acknowledgements}

This research was supported by the Khon Kaen University through the Cholangiocarcinoma Screening Care Program (Project No. CASCAP-09) to WL and the Invitation Research Fund, Faculty of Medicine, Khon Kaen University, Thailand to P.P. and W.L. (Project No. IN62312). We thank Professor Trevor N. Petney for editing the MS via the Publication Clinic KKU, Thailand.

\section{References}

1 Khuntikeo N, Titapun A, Loilome W, Yongvanit P, Thinkhamrop B, Chamadol N, Boonmars T, Nethanomsak T, Andrews RH, Petney TN and Sithithaworn P: Current perspectives on opisthorchiasis control and cholangiocarcinoma detection in southeast Asia. Front Med 5: 117, 2018. PMID: 29765958. DOI: 10.3389/fmed.2018.00117

2 Alsaleh M, Leftley Z, Barbera TA, Sithithaworn P, Khuntikeo N, Loilome W, Yongvanit P, Cox IJ, Chamodol N, Syms RR, Andrews RH and Taylor-Robinson SD: Cholangiocarcinoma: A guide for the nonspecialist. Int J Gen Med 12: 13-23, 2019. PMID: 30588065. DOI: 10.2147/IJGM.S186854

3 Yongvanit $\mathrm{P}$, Pinlaor S and Bartsch $\mathrm{H}$ : Oxidative and nitrative DNA damage: Key events in opisthorchiasis-induced carcinogenesis. Parasitol Int 61(1): 130-135, 2012. PMID: 21704729. DOI: 10.1016/j.parint.2011.06.011

4 Bhamarapravati $\mathrm{N}$, Thammavit $\mathrm{W}$ and Vajrasthira S: Liver changes in hamsters infected with a liver fluke of Man, Opisthorchis viverrini. Am J Trop Med Hyg 27(4): 787-794, 1978. PMID: 686245. DOI: 10.4269/ajtmh.1978.27.787

5 Thamavit W, Bhamarapravati N, Sahaphong S, Vajrasthira S and Angsubhakorn S: Effects of dimethylnitrosamine on induction of cholangiocarcinoma in Opisthorchis viverrini-infected Syrian golden hamsters. Cancer Res 38(12): 4634-4639, 1978. PMID: 214229 .
6 Loilome W, Yongvanit P, Wongkham C, Tepsiri N, Sripa B, Sithithaworn P, Hanai S and Miwa M: Altered gene expression in Opisthorchis viverrini-associated cholangiocarcinoma in hamster model. Mol Carcinog 45(5): 279-287, 2006. PMID: 16550611. DOI: $10.1002 / \mathrm{mc} .20094$

7 Jamnongkan W, Thanee M, Yongvanit P, Loilome W, Thanan R, Kimawaha P, Boonmars T, Silakit R, Namwat N and Techasen A: Antifibrotic effect of xanthohumol in combination with praziquantel is associated with altered redox status and reduced iron accumulation during liver fluke-associated cholangiocarcinogenesis. Peer J 6: e4281, 2018. PMID: 29375936. DOI: 10.7717/peerj.4281

8 Kaushik AK and DeBerardinis RJ: Applications of metabolomics to study cancer metabolism. Biochim Biophys Acta Rev Cancer 1870(1): 2-14, 2018. PMID: 29702206. DOI: 10.1016/j.bbcan. 2018.04.009

9 Sharif AW, Williams HR, Lampejo T, Khan SA, Bansi DS, Westaby D, Thillainayagam AV, Thomas HC, Cox IJ and TaylorRobinson SD: Metabolic profiling of bile in cholangiocarcinoma using in vitro magnetic resonance spectroscopy. HPB 12(6): 396402, 2010. PMID: 20662790. DOI: 10.1111/j.1477-2574.2010. 00185.x

10 Alsaleh M, Leftley Z, Barbera TA, Koomson LK, Zabron A, Crossey MME, Reeves HL, Cramp M, Ryder S, Greer S, Prince M, Sithithaworn P, Shariff M, Khuntikeo N, Loilome W, Yongvanit P, Shen YL, Cox IJ, Williams R, Wadsworth CA, Holmes E, Nash K and Taylor-Robinson SD: Characterisation of the serum metabolic signature of cholangiocarcinoma in a United Kingdom cohort. J Clin Exp Hepatol 10(1): 17-29, 2020. PMID: 32025163. DOI: 10.1016/j.jceh.2019.06.001

11 Alsaleh M, Sithithaworn P, Khuntikeo N, Loilome W, Yongvanit P, Chamadol N, Hughes T, O'Connor T, Andrews RH, Holmes $\mathrm{E}$ and Taylor-Robinson SD: Characterisation of the urinary metabolic profile of liver fluke-associated cholangiocarcinoma. J Clin Exp Hepatol 9(6): 657-675, 2019. PMID: 31889746. DOI: 10.1016/j.jceh.2019.06.005

12 Harrigan GG and Goodacre R: Metabolic Profiling: Its Role in Biomarker Discovery and Gene Function Analysis. Kluwer Academic: Boston, Mass., 2003.

13 Ranjan R and Sinha N: Nuclear magnetic resonance (NMR)based metabolomics for cancer research. NMR Biomed 32(10): e3916, 2019. PMID: 29733484. DOI: 10.1002/nbm.3916

$14 \mathrm{Gu} \mathrm{W}$ and Tong Z: Clinical application of metabolomics in pancreatic diseases: A mini-review. Lab Med 51(2): 116-121, 2020. PMID: 31340007 . DOI: 10.1093/labmed/lmz046

15 Wang L, Liu X and Yang Q: Application of metabolomics in cancer research: As a powerful tool to screen biomarker for diagnosis, monitoring and prognosis of cancer. Biomark J 4(3): 12, 2018. DOI: $10.21767 / 2472-1646.100050$

16 Wang H, Zhang H, Deng P, Liu C, Li D, Jie H, Zhang H, Zhou $\mathrm{Z}$ and Zhao YL: Tissue metabolic profiling of human gastric cancer assessed by (1)h nmr. BMC Cancer 16: 371, 2016. PMID: 27356757. DOI: 10.1186/s12885-016-2356-4

17 Yusof HM, Ab-Rahim S, Suddin LS, Saman MSA and Mazlan M: Metabolomics profiling on different stages of colorectal cancer: A systematic review. Malays J Med Sci 25(5): 16-34, 2018. PMID: 30914860. DOI: 10.21315/mjms2018.25.5.3

18 Budhu A, Terunuma A, Zhang G, Hussain SP, Ambs S and Wang $\mathrm{XW}$ : Metabolic profiles are principally different between cancers of the liver, pancreas and breast. Int J Biol Sci 10(9): 966-972, 2014. PMID: 25210494. DOI: 10.7150/ijbs. 9810 
19 OuYang D, Xu J, Huang H and Chen Z: Metabolomic profiling of serum from human pancreatic cancer patients using ${ }^{1} \mathrm{H}$ NMR spectroscopy and principal component analysis. Appl Biochem Biotechnol 165(1): 148-154, 2011. PMID: 21505807. DOI: 10.1007/s12010-011-9240-0

20 Lima AR, Bastos Mde L, Carvalho M and Guedes de Pinho P: Biomarker discovery in human prostate cancer: An update in metabolomics studies. Transl Oncol 9(4): 357-370, 2016. PMID: 27567960. DOI: 10.1016/j.tranon.2016.05.004

21 Beckonert O, Keun HC, Ebbels TM, Bundy J, Holmes E, Lindon JC and Nicholson JK: Metabolic profiling, metabolomic and metabonomic procedures for nmr spectroscopy of urine, plasma, serum and tissue extracts. Nat Protoc 2(11): 2692-2703, 2007. PMID: 18007604. DOI: 10.1038/nprot.2007.376

22 Dona AC, Jimenez B, Schafer H, Humpfer E, Spraul M, Lewis MR, Pearce JT, Holmes E, Lindon JC and Nicholson JK: Precision high-throughput proton $\mathrm{nmr}$ spectroscopy of human urine, serum, and plasma for large-scale metabolic phenotyping. Anal Chem 86(19): 9887-9894, 2014. PMID: 25180432. DOI: $10.1021 /$ ac5025039

23 Serkova NJ, Davis DM, Steiner J and Agarwal R: Quantitative nmr-based metabolomics on tissue biomarkers and its translation into in vivo magnetic resonance spectroscopy. Methods Mol Biol 1978: 369-387, 2019. PMID: 31119675. DOI: 10.1007/978-14939-9236-2_23

24 Dieterle F, Ross A, Schlotterbeck G and Senn H: Probabilistic quotient normalization as robust method to account for dilution of complex biological mixtures. Application in ${ }^{1} \mathrm{H}$ NMR metabonomics. Anal Chem 78(13): 4281-4290, 2006. PMID: 16808434. DOI: $10.1021 / \mathrm{ac} 051632 \mathrm{c}$

25 van den Berg RA, Hoefsloot HC, Westerhuis JA, Smilde AK and van der Werf MJ: Centering, scaling, and transformations: Improving the biological information content of metabolomics data. BMC Genomics 7: 142, 2006. PMID: 16762068. DOI: 10.1186/1471-2164-7-142

26 Worley B and Powers R: Pca as a practical indicator of OPLSDA model reliability. Curr Metabolomics 4(2): 97-103, 2016. PMID: 27547730. DOI: 10.2174/2213235X04666160613122429

27 Worley B and Powers R: Multivariate analysis in metabolomics. Curr Metabolomics 1(1): 92-107, 2013. PMID: 26078916. DOI: $10.2174 / 2213235 X 11301010092$

28 Posma JM, Robinette SL, Holmes E and Nicholson JK: Metabonetworks, an interactive matlab-based toolbox for creating, customizing and exploring sub-networks from KEGG. Bioinformatics 30(6): 893-895, 2014. PMID: 24177720. DOI: 10.1093/bioinformatics/btt612

29 Wonkchalee N, Boonmars T, Laummaunwai P, Aromdee C, Hahnvajanawong $\mathrm{C}$, Wu Z, Sriraj P, Aukkanimart R, Chamgramol Y, Pairojkul C, Juasook A and Sudsarn P: A combination of praziquantel and the traditional medicinal plant Thunbergia laurifolia on Opisthorchis viverrini infection and cholangiocarcinoma in a hamster model. Parasitol Res 112(12): 4211-4219, 2013. PMID: 24057695. DOI: 10.1007/s00436-0133613-y

30 Techasen A, Loilome W, Namwat N, Dokduang H, Jongthawin $\mathrm{J}$ and Yongvanit P: Cytokines released from activated human macrophages induce epithelial mesenchymal transition markers of cholangiocarcinoma cells. Asian Pac J Cancer Prev 13(Suppl): 115-118, 2012. PMID: 23480772. DOI: 10.7314/APJCP.2012.13. KKSuppl.115
31 Ghosh CC, Ramaswami S, Juvekar A, Vu HY, Galdieri L, Davidson D and Vancurova I: Gene-specific repression of proinflammatory cytokines in stimulated human macrophages by nuclear ikappabalpha. J Immunol 185(6): 3685-3693, 2010. PMID: 20696864. DOI: 10.4049/jimmunol.0902230

32 Jang CH, Choi JH, Byun MS and Jue DM: Chloroquine inhibits production of tnf-alpha, IL-1beta and IL-6 from lipopolysaccharide-stimulated human monocytes/macrophages by different modes. Rheumatology 45(6): 703-710, 2006. PMID: 16418198. DOI: 10.1093/rheumatology/kei282

33 Marton A, Pacher P, Murthy KG, Nemeth ZH, Hasko G and Szabo C: Anti-inflammatory effects of inosine in human monocytes, neutrophils and epithelial cells in vitro. Int J Mol Med 8(6): 617-621, 2001. PMID: 11712075.

34 Soliman ML, Puig KL, Combs CK and Rosenberger TA: Acetate reduces microglia inflammatory signaling in vitro. $\mathrm{J}$ Neurochem 123(4): 555-567, 2012. PMID: 22924711. DOI: 10.1111/j.14714159.2012.07955.x

35 Bunnag D and Harinasuta T: Studies on the chemotherapy of human opisthorchiasis in thailand: I. Clinical trial of praziquantel. Southeast Asian J Trop Med Public Health 11(4): 528-531, 1980. PMID: 7013095.

36 Pinlaor S, Prakobwong S, Boonmars T, Wongkham C, Pinlaor P and Hiraku Y: Effect of praziquantel treatment on the expression of matrix metalloproteinases in relation to tissue resorption during fibrosis in hamsters with acute and chronic Opisthorchis viverrini infection. Acta Trop 111(2): 181-191, 2009. PMID: 19427296. DOI: 10.1016/j.actatropica.2009.04.011

37 Duenngai K, Boonmars T, Sithithaworn J and Sithithaworn P: Diagnosis of early infection and post chemotherapeutic treatment by copro-DNA detection in experimental opisthorchiasis. Parasitol Res 112(1): 271-278, 2013. PMID: 23052766. DOI: 10.1007/s00436-012-3134-0

38 Lovis L, Mak TK, Phongluxa K, Aye Soukhathammavong P, Vonghachack Y, Keiser J, Vounatsou P, Tanner M, Hatz C, Utzinger $\mathrm{J}$, Odermatt $\mathrm{P}$ and Akkhavong $\mathrm{K}$ : Efficacy of praziquantel against Schistosoma mekongi and Opisthorchis viverrini: A randomized, single-blinded dose-comparison trial. PLoS Negl Trop Dis 6(7): e1726, 2012. PMID: 22848766. DOI: 10.1371/journal.pntd.0001726

39 DeBerardinis RJ and Chandel NS: Fundamentals of cancer metabolism. Sci Adv 2(5), 2016. PMID: 27386546. DOI: 10.1126/sciadv. 1600200

40 Warburg O, Wind F and Negelein E: The metabolism of tumors in the body. J Gen Physiol 8(6): 519-530, 1927. PMID: 19872213. DOI: 10.1085 /jgp.8.6.519

41 Ahn CS and Metallo CM: Mitochondria as biosynthetic factories for cancer proliferation. Cancer Metab 3(1): 1, 2015. PMID: 25621173. DOI: 10.1186/s40170-015-0128-2

42 Owen OE, Kalhan SC and Hanson RW: The key role of anaplerosis and cataplerosis for citric acid cycle function. J Biol Chem 277(34): 30409-30412, 2002. PMID: 12087111. DOI: $10.1074 /$ jbc.R200006200

43 Giskeodegard GF, Lundgren S, Sitter B, Fjosne HE, Postma G, Buydens LMC, Gribbestad IS and Bathen TF: Lactate and glycine-potential MR biomarkers of prognosis in estrogen receptor-positive breast cancers. NMR Biomed 25(11): 12711279, 2012. PMID: 22407957. DOI: 10.1002/nbm.2798

44 Liu KA, Lashinger LM, Rasmussen AJ and Hursting SD: Leucine supplementation differentially enhances pancreatic 
cancer growth in lean and overweight mice. Cancer Metab 2(1): 6, 2014. PMID: 24685128. DOI: 10.1186/2049-3002-2-6

45 Katz-Brull R, Seger D, Rivenson-Segal D, Rushkin E and Degani $\mathrm{H}$ : Metabolic markers of breast cancer: Enhanced choline metabolism and reduced choline-ether-phospholipid synthesis. Cancer Res 62(7): 1966-1970, 2002. PMID: 11929812.

46 Ueland PM: Choline and betaine in health and disease. J Inherit Metab Dis 34(1): 3-15, 2011. PMID: 20446114. DOI: 10.1007/ s10545-010-9088-4

47 Rocha CM, Barros AS, Gil AM, Goodfellow BJ, Humpfer E, Spraul M, Carreira IM, Melo JB, Bernardo J, Gomes A, Sousa V, Carvalho L and Duarte IF: Metabolic profiling of human lung cancer tissue by $1 \mathrm{H}$ high resolution magic angle spinning (HRMAS) NMR spectroscopy. J Proteome Res 9(1): 319-332, 2010. PMID: 19908917. DOI: 10.1021/pr9006574

48 Shariff MI, Gomaa AI, Cox IJ, Patel M, Williams HR, Crossey MM, Thillainayagam AV, Thomas HC, Waked I, Khan SA and Taylor-Robinson SD: Urinary metabolic biomarkers of hepatocellular carcinoma in an Egyptian population: A validation study. J Proteome Res 10(4): 1828-1836, 2011. PMID: 21275434. DOI: $10.1021 / \mathrm{pr} 101096 \mathrm{f}$

49 da Silva RP, Nissim I, Brosnan ME and Brosnan JT: Creatine synthesis: Hepatic metabolism of guanidinoacetate and creatine in the rat in vitro and in vivo. Am J Physiol Endocrinol Metab 296(2): E256-261, 2009. PMID: 19017728. DOI: 10.1152/ajpendo. 90547.2008

50 Litwack G: Human Biochemistry. Elsevier/Academic Press: London, United Kingdom, 2018.

51 Yamashita H, Kaneyuki T and Tagawa K: Production of acetate in the liver and its utilization in peripheral tissues. Biochim Biophys Acta 1532(1-2): 79-87, 2001. PMID: 11420176. DOI: 10.1016/s1388-1981(01)00117-2

52 Bruzzone C, Loizaga-Iriarte A, Sanchez-Mosquera P, Gil-Redondo R, Astobiza I, Diercks T, Cortazar AR, Ugalde-Olano A, Schafer H, Blanco FJ, Unda M, Cannet C, Spraul M, Mato JM, Embade $\mathrm{N}$, Carracedo A and Millet O: (1)H NMR-based urine metabolomics reveals signs of enhanced carbon and nitrogen recycling in prostate cancer. J Proteome Res 19(6): 2419-2428, 2020. PMID: 32380831. DOI: 10.1021/acs.jproteome.0c00091

53 Schug ZT, Vande Voorde J and Gottlieb E: The metabolic fate of acetate in cancer. Nat Rev Cancer 16(11): 708-717, 2016. PMID: 27562461. DOI: 10.1038/nrc.2016.87

54 Kendrick SF, O’Boyle G, Mann J, Zeybel M, Palmer J, Jones $\mathrm{DE}$ and Day CP: Acetate, the key modulator of inflammatory responses in acute alcoholic hepatitis. Hepatology 51(6): 19881997, 2010. PMID: 20232292. DOI: 10.1002/hep.23572

55 Jabs CM, Neglen P and Eklof B: Breakdown of adenine nucleotides, formation of oxygen free radicals, and early markers of cellular injury in endotoxic shock. Eur J Surg 161(3): 147155, 1995. PMID: 7599292.
56 Fini MA, Elias A, Johnson RJ and Wright RM: Contribution of uric acid to cancer risk, recurrence, and mortality. Clin Transl Med 1(1): 16, 2012. PMID: 23369448. DOI: 10.1186/20011326-1-16

57 Hasko G, Kuhel DG, Nemeth ZH, Mabley JG, Stachlewitz RF, Virag L, Lohinai Z, Southan GJ, Salzman AL and Szabo C: Inosine inhibits inflammatory cytokine production by a posttranscriptional mechanism and protects against endotoxininduced shock. J Immunol 164(2): 1013-1019, 2000. PMID: 10623851. DOI: 10.4049/jimmunol.164.2.1013

58 Cernei N, Zitka O, Skalickova S, Gumulec J, Sztalmachova M, Rodrigo MA, Sochor J, Masarik M, Adam V, Hubalek J, Trnkova L, Kruseova J, Eckschlager T and Kizek R: Effect of sarcosine on antioxidant parameters and metallothionein content in the PC-3 prostate cancer cell line. Oncol Rep 29(6): 24592466, 2013. PMID: 23588590. DOI: 10.3892/or.2013.2389

59 Huang YC, Chen M, Shyr YM, Su CH, Chen CK, Li AF, Ho DM and Chen YM: Glycine n-methyltransferase is a favorable prognostic marker for human cholangiocarcinoma. J Gastroenterol Hepatol 23(9): 1384-1389, 2008. PMID: 18624901. DOI: $10.1111 /$ j.1440-1746.2008.05488.x

60 Holzinger F, Z'Graggen K and Buchler MW: Mechanisms of biliary carcinogenesis: A pathogenetic multi-stage cascade towards cholangiocarcinoma. Ann Oncol 10: 122-126, 1999. PMID: 10436802. DOI: 10.1093/annonc/10.suppl_4.S122

61 Sirica AE: Cholangiocarcinoma: Molecular targeting strategies for chemoprevention and therapy. Hepatology 41(1): 5-15, 2005. PMID: 15690474. DOI: 10.1002/hep.20537

62 Sripa B, Kaewkes S, Sithithaworn P, Mairiang E, Laha T, Smout M, Pairojkul C, Bhudhisawasdi V, Tesana S, Thinkamrop B, Bethony JM, Loukas A and Brindley PJ: Liver fluke induces cholangiocarcinoma. PLoS Med 4(7): e201, 2007. PMID: 17622191. DOI: 10.1371/journal.pmed.0040201

63 Dokduang H, Techasen A, Namwat N, Khuntikeo N, Pairojkul C, Murakami Y, Loilome W and Yongvanit P: Stats profiling reveals predominantly-activated STAT3 in cholangiocarcinoma genesis and progression. J Hepatobiliary Pancreat Sci 21(10): 767-776, 2014. PMID: 25044480. DOI: 10.1002/jhbp.131

64 Ishimura N, Isomoto H, Bronk SF and Gores GJ: TRAIL induces cell migration and invasion in apoptosis-resistant cholangiocarcinoma cells. Am J Physiol Gastrointest Liver Physiol 290(1): G129-136, 2006. PMID: 16166346. DOI: 10.1152/ajpgi.00242.2005 